Available online on 15.05.2019 at http://ujpr.org
Universal Journal of Pharmaceutical Research
An International Peer Reviewed Journal
Open access to Pharmaceutical research is an open access article distributed under the terms of the Creative Commons Attribution-Non
Commercial Share Alike 4.0 License which permits unrestricted non commercial use,
provided the original work is properly cited
Volume 4, Issue 2, 2019

\title{
USE OF DIOSGENIN, YAMOGENIN, TIGOGENIN AND NEOTIGOGENIN FOR TREATMENT OF HYPERLIPIDEMIA BY INHIBITING CHOLESTEROL ABSORPTION IN GIT

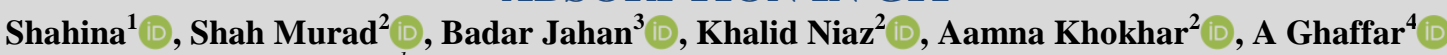 \\ ${ }^{1}$ Biochemistry, KIMS Malir Cantt Karachi, Pakistan. \\ ${ }^{2}$ Akbar Niazi Teaching Hospital- IMDC, Islamabad, Pakistan. \\ ${ }^{3}$ MSBBMC, Layari Karahi, Pakistan. \\ ${ }^{4} I M D C$ and DANTH, Islamabad, Pakistan.
}

\section{ABSTRACT}

Objective: High plasma lipids interact with free radicals in human body leading to develop coronary artery disease. We in this study have compared hypolipidemic effects of Fenugreek, Curcuma Longa, and lemon.

Methods: Study was conducted at Jinnah Hospital Lahore-Pakistan from January 2018 to May 2018. Ninety hyperlipidemic patients of age Group 19 to 70 were included in the study. Exclusion criteria were diabetic, alcoholic additives, hypertensive patients and those whose kidney or liver functions were impaired. Consent was taken from all participants. Their base line lipid profile was taken in biochemistry laboratory of the hospital. They were divided in three Groups i.e. 30 patients in each Group. Group-I was advised to take $500 \mathrm{mg}$ of Curcuma longa (haldi) mixed in fresh milk without cream, thrice daily for two months. Group-II patients were advised to take 100 grams of Fenugreek leaves mixed with salad in each meal (thrice daily) for the period of two months. Group-III patients were advised to take $40 \mathrm{ml}$ of fresh lemon juice mixed with $40 \mathrm{ml}$ mineral water thrice daily for two months. They all were advised not to take heavy meal rich with any type of fat like junk food etc. One hour daily brisk walk was advised to all participants. 15 days follow up visit was scheduled for them. After two months their lipid profile was redetermined.

Results: When results were compiled and statistically analyzed by applying paired ' $\mathrm{t}$ ' test, it revealed that Curcuma longa decreased total cholesterol, TG, LDL cholesterol 16.10, 20.01, and $17.59 \mathrm{mg} / \mathrm{dl}$ respectively. Fenugreek decreased total cholesterol, TGs, and LDL cholesterol 14.70, 17.33, and $17.06 \mathrm{mg} / \mathrm{dl}$ respectively. Lemon in two months therapy decreased total cholesterol, TGs, and LDL cholesterol 15.45, 10.13, and $11.97 \mathrm{mg} / \mathrm{dl}$ respectively. None of the above mentioned herbs raised HDL cholesterol significantly.

Conclusion: It was concluded from this research work that Curcuma Longa, Fenugreek leaves and Lemon are mild to moderately effective hypolipidemic herbs to lower total plasma cholesterol, triglycerides, and LDL cholesterol but have no potential to raise HDL cholesterol when analyzed biostatistically.

Keywords: Curcuma Longa, exclusion criteria, heavy meal, hypolipidemic effects, Jinnah Hospital.

Article Info: Received 8 March 2019; Revised 4 April; Accepted 28 April, Available online 15 May 2019

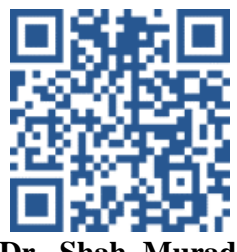

\section{Cite this article-}

Shahina, Murad S, Jahan B, Niaz K, Khokhar A, Ghaffar A. Use of diosgenin, yamogenin, tigogenin and neotigogenin for treatment of hyperlipidemia by inhibiting cholesterol absorption in GIT. Universal Journal of Pharmaceutical Research 2019; 4(2): 34-37.

DOI: https://doi.org/10.22270/ujpr.v4i2.255

Address for Correspondence

Dr. Shah Murad, Pharmacology Deptt: Akbar Niazi Teaching Hospital and IMDC, affiliated with SZABMU, Islamabad, Pakistan. E-mail: shahhmurad65@gmail.com

\section{INTRODUCTION}

Atherosclerotic problems are encountered with enhancement of LDL uptake by monocytes and macrophages ${ }^{1,2}$. In the liver, uptake of plasma LDL is mediated via specific LDL receptors, but a scavenger receptor system is employed by macrophages. Plasma LDL must be modified prior to uptake by macrophages. Analysis of the lipid content in the oxidatively modified LDL from hyper lipidemic patients revealed that the level of lysophosphatidylcholine was greatly elevated, and the high level of the lysolipid was shown to impair the endotheliumdependent relaxation of the blood vessels ${ }^{3-7}$. In alllopathy blood lipid levels are normalized by statins, fibrates, niacin and bile acid binding resins (BABRs). All of these allopathy related drugs have low compliance ranges from mild compliance due to metalic taste of BABRs to severe side effects like 
rhabdomyolysis by fibrates and statins ${ }^{8}$. Due to low compliance and adverse effects of conventionally used hypolipidemic agents, herbal medicines are going to be famous among Physicians, and Cardiologists'. Medicinal herbs like Curcuma Longa, Fenugreek, and Lemon contents are being used as mild to moderate hypolipidemic agents. Curcuma longa commonly known as Haldi in India and Pakistan is used to lower plasma lipids, in view of their contents. It contains curcuminoids (curcumin, demethoxycurcumin, and bisdemethoxycurcumin), turmerone, atlantone, zingiberene, proteins, and resins ${ }^{10}$. Curcumin reduces both the oxidation and circulation of oxidized levels of LDL cholesterol which leads to reduction in the occurrence or treatment of already present atherosclerosis in the subjects ${ }^{11}$. Research has revealed that curcumin from turmeric is an extremely efficient agent in increasing cholesterol uptake by the liver cells $^{12}$. Several independent studies have shown that curcumin increases the expression of cholesterol and lipoprotein receptors on the liver cells ${ }^{13}$.

Table 1: Showing parameters values before and after treatment with their statistical significance in Group-1 $(n=29)(C$. longa or haldi).

\begin{tabular}{lcccc}
\hline Values & Day 0 & Day 60 & $\begin{array}{c}\text { Difference } \\
\text { in mg/dl }\end{array}$ & $\boldsymbol{P}$-value \\
\hline TC & $271.87 \pm 1.04$ & $255.77 \pm 2.77$ & 16.10 & $<0.001$ \\
TG & $216.09 \pm 2.43$ & $196.08 \pm 2.45$ & 20.01 & $<0.001$ \\
LDL-C & $179.65 \pm 2.87$ & $162.06 \pm 2.51$ & 17.59 & $<0.001$ \\
HDL-C & $37.95 \pm 1.45$ & $41.65 \pm 1.91$ & 3.70 & $<0.001$ \\
\hline
\end{tabular}

Table 2: Showing parameters values before and after treatment with their statistical significance in Group-2 $(n=28)$ (Fenugreek or methi).

\begin{tabular}{lcccc}
\hline Values & Day 0 & Day 60 & $\begin{array}{c}\text { Difference } \\
\text { in mg/dl }\end{array}$ & $\boldsymbol{P}$-value \\
\hline TC & $280.56 \pm 1.06$ & $265.86 \pm 2.65$ & 14.70 & $<0.001$ \\
TG & $224.87 \pm 1.55$ & $207.54 \pm 1.98$ & 17.33 & $<0.001$ \\
LDL-C & $213.13 \pm 2.78$ & $196.07 \pm 1.56$ & 17.06 & $<0.001$ \\
HDL-C & $35.19 \pm 2.32$ & $38.08 \pm 1.67$ & 2.89 & $<0.001$ \\
\hline
\end{tabular}

Curcumin also increases cholesterol and bile acids excretion in feces ${ }^{14}$. Additionally, curcumin also increases the amount of ABC (ATP-binding cassette) transporters. These transporters are basically involved in flushing out excess cholesterol from the inside of the macrophages. When the numbers of $\mathrm{ABC}$ transporters are increased on the surface of a macrophage, the deposited cholesterol is effluxes out through these channels again into the blood. Through the blood, it reaches liver where it is metabolized efficiently ${ }^{15}$. The composition of fenugreek includes a large number of chemical components. They include proteins and amino acids, flavonoids, saponins and steroidal saponins, coumarin, lipids, vitamins, minerals, galactomannan fiber and alkaloids, such as trigonelline. Extracts are available standardized to contain 50 percent saponins or 20 percent of the amino acid 4hydroxyisoleucine ${ }^{16}$. Treatment with fenugreek seed powder normalized the enhanced lipid peroxidation and increased susceptibility to oxidative stress associated with depletion of antioxidants ${ }^{17}$. The steroidal saponins (diosgenin, yamogenin, tigogenin and neotigogenin) are thought to inhibit cholesterol absorption and synthesis and hence its potential role in arteriosclerosis $^{18}$. Phenolics in C. longa have potential health benefits mainly due to their antioxidant properties such as reactive oxygen species (ROS) scavenging and inhibition, electrophile scavenging and metal chelation ${ }^{19}$. Epidemiological studies support a relationship between the consumption of phenolic rich food products and a low incidence of coronary heart disease, atherosclerosis, certain forms of cancer and stroke $^{20}$. Lipid peroxidation is inhibited by flavonoids and flavanones present in Lemon ${ }^{21}$.

\section{PATIENTS AND METHOD}

\section{Place and period of research work}

The research work was conducted at Jinnah Hospital, Lahore from January 2018 to May 2018 with approval of Research ethics committee of the Hospital. SAMPLE SIZE: Ninety hyperlipidemic patients were selected for research work. CONSENT: Written consent was taken from all patients. Specific Performa was designed for the research work. Hyperlipidemic patients were selected with age range from 19 to 70 years.

\section{Exclusion criteria}

Exclusion criteria were hypertension, hypothyroidism, diabetes mellitus, alcohol addictive patients, peptic ulcer, any gastrointestinal upset, renal impairment, and any hepatic or cardiac problem.

\section{Grouping}

All patients were divided in three Groups (Group-I, Group-II, Group-III), 30 patients in each Group. Their baseline lipid profile data were taken and filed in specifically designed Performa, at start of taking medicine, like lipid profile, blood pressure and pulse rate.

\section{Lipid profile}

Serum lipid profile (total cholesterol, HDL-cholesterol, triglyceride) parameters were determined after a 12 hour overnight fast by standard methods. LDLcholesterol level was calculated according to the Friedewald's formula.

Thirty patients of Group-I were advised to take $500 \mathrm{mg}$ of $C$. longa (haldi) mixed in fresh milk without cream, thrice daily for two months. Group-II patients were advised to take 100 grams of Fenugreek leaves mixed with salad in each meal (thrice daily) for the period of 
two months. Group-III patients were advised to take 40 $\mathrm{ml}$ of fresh lemon juice mixed with $40 \mathrm{ml}$ mineral water thrice daily for two months. They all were advised not to take heavy meal rich with any type of fat like junk food etc. One hour daily brisk walk was advised to all participants. 15 days follow up visit was scheduled for them. After two months their lipid profile was re-determined.

Table 3: Showing parameters values before and after treatment with their statistical significance in Group-3

\begin{tabular}{lcccc}
\multicolumn{5}{c}{$(\mathbf{n}=\mathbf{2 9})($ Lemon water). } \\
\hline Values & Day 0 & Day 60 & $\begin{array}{c}\text { Difference } \\
\text { in } \mathbf{~ m g / d l}\end{array}$ & $\boldsymbol{P}$-value \\
\hline TC & $258.21 \pm 2.12$ & $242.76 \pm 1.89$ & 15.45 & $>0.05$ \\
TG & $246.56 \pm 2.11$ & $236.43 \pm 2.43$ & 10.13 & $>0.05$ \\
LDL-C & $179.08 \pm 2.87$ & $167.11 \pm 1.77$ & 11.97 & $>0.05$ \\
HDL-C & $36.22 \pm 1.77$ & $39.77 \pm 1.55$ & 3.55 & $>0.05$ \\
\hline
\end{tabular}

Key: All values are written in mean and \pm stands for standard error of mean. $\mathrm{T}-\mathrm{C}=$ serum total cholesterol, $\mathrm{TG}=\mathrm{serum}$ triglycerides, $\mathrm{LDL}-\mathrm{C}=\mathrm{low}$ density lipoprotein cholesterol, HDL-C $=$ high density lipoprotein cholesterol. All parameters pre and post-treatment are measured in mg/d. $\mathrm{n}=$ sample size. $P$-value $<0.01$ stands for significant change, $p$-value $>0.05$ stands for non-significant change.

\section{Statistical analysis}

Mean values of the day- 0 and day- 60 of tested parameters (total cholesterol, LDL cholesterol, triglycerides, and HDL cholesterol) \pm SD were taken to be analyzed statistically. SPSS 10 version 2.00.01.10 was used to analyze pretreatment and post treatment values of all parameters. Paired't' test was applied to determine changes in pre and post treatment values. $P$ value $>0.05$ was considered as non significant changes in tested parameters, and $p$-values $<0.01$ were considered as significant changes

\section{RESULTS}

When results were compiled and statistically analyzed by using SPSS 10 version 02.00.01.10, it revealed that C. longa decreased triglycerides (TG), total cholesterol (TC), and LDL cholesterol of 29 hyperlipidemic patients $20.01,16.10$, and $17.59 \mathrm{mg} / \mathrm{dl}$ respectively. Raise in HDL cholesterol in this Group was 03.70 $\mathrm{mg} / \mathrm{dl}$. Fenugreek leaves reduced TG, TC, LDL cholesterol of 28 hyperlipidemic patients 17.33, 14.70, and $17.06 \mathrm{mg} / \mathrm{dl}$ respectively. Lemon juice reduced TC, TG, and LDL cholesterol 15.45, 10.13, and 11.97 $\mathrm{mg} / \mathrm{dl}$ respectively. HDL raised $03.55 \mathrm{mg} / \mathrm{dl}$ in this Group. Changes in all tested parameters, and their statistical significance are shown in following table.

\section{DISCUSSION}

Only normal levels of plasma lipid could be preventive measure of all these diseased states. In current results lemon, curcula longa, and Fenugreek proved that significant reduction occurs in TC, TG, LDL, cholesterol by using these herbal preparation/mixture. But all of these three herbs have no significant influence on HDL cholesterol. Same results did prove in the study conducted by Wiseman et al., ${ }^{22}$ who described that pectin present in these three herbs inhibit enterohepatic circulation of bile acids and excrete cholesterol in feces. Flavanoids present in Fenugreek are responsible for inhibition of cholesterol synthesis ${ }^{23}$. Gidez et al., ${ }^{24}$ stated that herbal medications have more than one or two mechanism to balance plasma lipids in hyperlipidemic patients. Bingham et al., ${ }^{25}$ stated that the major reasons for hypercholesterolemia in today's world are obesity, consuming high fat food, diabetes and having a family history of high cholesterol. This disorder is reported to affect a large number of people all across the world and is one of the leading causes of death as well. Cholesterol is reduced in the body by managing weight and diet. Regular exercise, lesser consumption of fatty foods, more consumption of fruits and vegetables help in ameliorating the symptoms of hypercholesterolemia. However, in most cases, medications also known as anti hypertensive and anti cholesterol drugs are also required, especially in chronic cases. There are several problems associated with medications though and people are now switching towards newer and less toxic therapies to control and reduce cholesterol levels in the body. Several natural herbs, supplements and food products are known to maintain healthy cholesterol levels and reduce cholesterol in mild hyper-cholesterolemia. These therapies, if opted for, help in preventing the disorder but are less helpful in chronic cases of this disease. In an experiment ${ }^{26}$, controlled dosing of turmeric was used to feed hypercholesterolemic rabbits and the effect on LDL oxidation was analyzed. It was found that turmeric extracts efficiently and quickly reduced the levels of cholesterol in the blood along with the incidences of atherosclerosis with time. The reason for these therapeutic effects, when analyzed, was found to be the preventive action of turmeric on the oxidation of LDL cholesterol. Mattern et al.,${ }^{27}$ have also explained same important mechanism of action of Turmeric that oil of these seeds inhibits enterohepatic circulation causing biosynthesis of bile acids instead of cholesterol by hepatocytes. The results obtained from research work conducted by Geleijnse et al. ${ }^{28}$ revealed that all extracts of the fenugreek exhibit antioxidant activity. These findings suggest that the fenugreek extracts could act as potent source of antioxidants. Magee et al., ${ }^{29}$ mentioned that many herbs and their constituents have potential to reduce total plasma cholesterol LDL cholesterol, and triglycerides but they do not raise HDL cholesterol because it needs special plasma proteins as lipoproteins responsible for structural and functional integrity of HDL particles. Jhumarr et al., ${ }^{30}$, Loversa et al., ${ }^{31}$, Hundahg et al., ${ }^{32}$, and Sueawath et al., ${ }^{33}$ described about citrus fruit Lemon that its Citric acid is antioxidant which lead to decrease oxidative stress in human body. 


\section{CONCLUSION}

Present study concludes that $C$. longa, Fenugreek leaves and Lemon are mild to moderately effective hypolipidemic herbs to lower total plasma cholesterol, triglycerides, and LDL cholesterol but have no potential to raise HDL cholesterol when analyzed biostatistically.

\section{ACKNOWLEDGEMENTS}

The authors extend their thanks and appreciation to the Akbar Niazi Teaching Hospital and IMDC to provide necessary facilities for this work.

\section{AUTHOR'S CONTRIBUTION}

The manuscript was carried out, written, and approved in collaboration with all authors.

\section{CONFLICT OF INTEREST}

No conflict of interest associated with this work

\section{REFERENCES}

1. Mert FF, Sanders TA, Wiseman H. Flavonoids protect against oxidative damage to LDL in vitro: use in selection of a flavonoid rich diet and relevance to LDL oxidation resistance ex vivo. J Folklore Res Rev 2013; 33(8):90-5.

2. Rouiy T, Pejuy T, Ferro-Luzzi, A. In vivo antioxidant effect of green and black tea in man. Ups J Med Sci 2011;33(2):444-9

3. Sath SA, Bouwens LC. The chemistry of tea flavonoids. World J Med Sci 2013; 66(8):323-8.

4. Yuth RE, Mwthy HG, Strain JJ. The ferric reducing ability of plasma (FRAP) as a measure of "antioxidant power": the FRAP assay. J Japanese Clin Micro 2012; 12(7):122-9. https://doi.org/10.1006/abio.1996.0292

5. Lothy R, Solvoll, K. and Foss, O. P. Tea consumption. Relationship to cholesterol, blood pressure, and coronary and total mortality. Jou Cl Nutr 2013; 777-9. https://doi.org/10.1016/0091-7435(92)90062-M

6. Solkth R, Thorpe, G. Atherosclerosis: newer view points. J Manag Pub Polic 2012; 4(12):90-5. https://doi.org/10.1186/1741-7015-11-117

7. Malner T, Wiseman SA. A single dose of tea with or without milk increases plasma antioxidant activity in humans. Ind J Nutr 2012; 54:87-92. https://doi.org/10.1038/sj.ejcn.1600900

8. Ito T, Yoshida H, Ayaori M, Nishiwaki M, Yonemura A, Hara Y, Nakamura H. Conventional hypolipidemic medicines and their compliance. Libyan J Nutr 2014; 66:261-266.

9. Sesso HD, Gaziano JM, Buring JE, Hennekens CH. Hypolipidemic constituents in herbs. J Epidemiol 2014; 149:162-167.

10. Hodgson JM, Puddey IB, Croft KD, Burke V, Mori TA, Caccetta RA, Beilin LJ. Chemical contents of Curcuma Longa. J Nutr 2014; 71:1103-1107.

11. Klatsky, A. L., Friedman, G. D. and Armstrong, M. A. Curcuma longa affects LDL oxidation. Med J Epidem 2012; $132: 479-488$

12. Hertog MG, Sweetnam PM, Fehily AM, Elwood PC, Kromhout D. Antioxidant flavonols and ischemic heart disease. Sr J Med 2013; 65:1489-1494. https://doi.org/10.1016/S0140-6736(05)60135-3
13. Kono S, Shinchi K, Ikeda N, Yanai F, Imanishi K. Miraculos hypolipidemic herb: curcuma longa. Japan Prev Med 2013;21:526-531.

14. Fogelman AM, Shechter I, Seager J, Hokom M, Child JS, Edwards PA. Curcuma longa inhibits enterohepatic circulation. J Sur and Med Ind 2015; 77:2214-2218.

15. Lowry $\mathrm{OH}$, Rosenbrough NJ, Farr AL, Randall RJ. ATPbinding cassette transporter and efflux of lipids. J Biol Chem 2013; 193:265-275. https://doi.org/10.1074/jbc.M704590200

16. keda I, Imasato Y, Sasaki E, Nakayama M, Nagao H, Takeo T, Yayabe F, Sugano M. Chemical compounds found in Fenugreek seeds. J Bioch 2013; 1127:141-146.

17. Yang CS, Landau JM. Handling LDL oxidation with herbal medicine. J Cl Nutr 2014; 130:2409-2412.

18. Keli SO, Hertog MG, Feskens EJ, Kromhout D. Dietary flavonoids, antioxidant vitamins, and incidence of stroke. J Med Sc 2014; 156:637-642. https://doi.org/10.2147/ciia.2007.2.1.147

19. Mukhtar H, Ahmad N. Metalic Chelation by Curamin. J Cl Med 2014; 71:1698S-1702S

https://doi.org/10.1016/j.ijbiomac.2015.11.092

20. Princen HM, Van Duyvenvoorde W, Buytenhek R, Blonk C, Tijburg LB, Langius JA, Meinders AE. Phenolic compond rich foods for cure of CAD. J Health Med Ethop 2014; 18:833-41.

21. Hertog MG, Feskens EJ, Hollman PC, Katan MB, Kromhout D. Lemon Juice for treating hyperlipidemia and CAD. J Ind Med 2015; 42:1007-11. https://doi.org/10.4103/2008-7802.187248

22. Wiseman SA, Balentine DA, Frei B. Antioxidant potential of pectin present in herbs. J Med Ir 2014; 37:705-18.

23. Tijburg LB, Mattern T, Folts JD, Weisgerber UM, Katan MB. Favonoids and cardiovascular disease: a review. J Biol Pk 2014; 37(2):771-85. https://doi.org/10.1111/j.1753-4887.2012.00508.x

24. Gidez LI, Miller GJ, Burstein M, Slagle S, Eder HA. MOA of hypolipidemic herbs. J of Med Therapy 2015; 23(4):20623. PMID: 26478732

25. Bingham SA, Vorster H, Jerling JC, Magee E, Mulligan A, Runswick SA, Cummings JH. Obesity, hypercholestrelemia, metabolic syndrome and options of their cure. Med J Prev Med 2015; 78(3):41-55 https://doi.org/10.1016/j.ejphar.2015.03.093

26. Reaven PD, Witztum JL. Oxidized low density lipoproteins in atherogenesis: role of dietary modification. J Ethop Med 2013;16(6):51-71 https://doi.org/10.1146/annurev.nu.16.070196.000411

27. Mattern T, Witztum JL, Weisgerber UM. Turmic seeds oil interupts enterohepatic circulation of Bas. $\mathrm{J}$ Lipid Res 2012;53: 2490-2514

28. Geleijnse JM, Launer LJ, Hofman A, Pols HA, Witteman JC. How fenugreek is antioxident? Food Sc 2014; 159:2170-74.

29. Magee E, Mulligan A, Constrv YL. Consumption of foods rich in flavonoids is related to a decreased cardiovascular risk. J Med Nutr 2014; 134:23-6. https://doi.org/10.1093/jn/134.4.923

30. Jhumarr J, Yulda C, Helov T. Fruits can prevent diseases. Mal J Nurs 2013; 8(7):99-104.

31. Loversa T, Mught R, Loferr T, Ilova H. Phytochemistry of some plants. Jou Cl Nutr Res 2013; 12(1):44-8.

32. Hundahg P, Urhav I, Ytrag R. Therapeutic approach with medicinal herbs. J Res Med Sci 2012; 7(5):66-80.

33. Sueawath JJ, Howan RR, Mekba TG, Illahu RF, Ulkav BT. Lemon is antioxidant fruit. Int J Reprod Biomed 2015; 7(6):111-9. 